\title{
APROXIMACIÓN A LOS ORÍGENES DE LA POLÍTICA EXTERIOR ESTADOUNIDENSE RESPECTO AL CONFLICTO PALESTINO-ISRAELÍ: EVOLUCIÓN HISTÓRICA Y GRUPOS DE PRESIÓN ${ }^{1}$
}

\author{
Ana Torres García \\ Universidad de Sevilla
}

\begin{abstract}
This article focuses on two aspects of the United States foreign policy towards the PalestinianIsraeli conflict. First, it presents a historical overview of the United States relations with Israel and with the Palestinians underlining the different phases that these bilateral relations have gone through since the establishment of the state of Israel. Secondly, it explains the linkage between domestic and foreign American policy through the analysis of the different roles played by the Jewish American community and the Arab and Muslim American communities in the U.S. political system, and how their respective lobbying efforts finally translate into the make-up of Congress.
\end{abstract}

La estrecha relación de Israel con Estados Unidos a lo largo de sus más de cincuenta años de existencia suscita un inmediato interrogante: ¿por qué? ¿Cómo es posible la existencia y mantenimiento de semejante alianza que permite a los estadounidenses apoyar de manera incondicional a Israel a pesar de la historia del conflicto palestino-israelí, sus consecuencias para la población de toda la región medio-oriental, no sólo la palestina, los graves abusos de derechos humanos que Israel ha cometido y comete dentro de los territorios ocupados e incluso contra parte de su propia población; en definitiva, su menosprecio por la ley internacional que se traduce, por ejemplo, en sistemáticas violaciones de la Convención de Ginebra y su incumplimiento de múltiples resoluciones de Naciones Unidas.

Más aún, su propio aliado tiene qué reprocharle a Israel. Además de arrastrar a los estadounidenses a intervenir en Oriente Medio (Líbano, 1982), Israel ha conspirado contra Estados Unidos (caso Lavon, 1954) ${ }^{2}$, bombardeó el navío de la Armada U.S.S. Liberty en

\footnotetext{
${ }^{1}$ Este artículo se redactó con ocasión de la participación de la autora con la conferencia titulada "Política de EE.UU. en el conflicto palestino-israelí" en el Seminario de Septiembre "La encrucijada de Palestina", dirigido por la profesora Dra. Dña Clara Thomas de Antonio y celebrado en la Facultad de Filología, Universidad de Sevilla, del 24 al 27 de septiembre de 2002. Aprovecho también estas líneas para agradecer a las siguientes personas su ayuda durante la elaboración de este artículo: Yaser Abushaban, Brenda Bickett, Vanesa Casanova Fernández, Khaled Elghindy, Keiko Ono y Margaret Zaknoen.
}

${ }^{2}$ Ante el anuncio de Gran Bretaña de su acuerdo con Egipto para evacuar sus tropas del Canal de Suez en 1954, los servicios de inteligencia israelíes planearon y ejecutaron una serie de ataques terroristas contra objetivos 
$1967^{3}$, ha espiado a su aliado (caso Pollard, 1985), engañó a las autoridades norteamericanas en lo referente al desarrollo de su arsenal nuclear y, por si fuera poco, en los últimos años se sospecha que Israel ha vendido tecnología militar cedida por Estados Unidos a terceros países.

A pesar de todo, Estados Unidos parece haber concedido carta blanca a Israel, ya que semejante actitud y acciones por cualquier otro país causarían una ola de rechazo sin precedentes que pondrían en serio peligro las relaciones entre ambos Estados. Sin embargo, y sorprendentemente, es muy difícil oir una voz firmemente crítica con Israel por parte de la clase política y la sociedad estadounidenses.

Esta realidad es difícil de entender para los no norteamericanos y se intenta explicar atribuyéndola a intereses económicos norteamericanos en la zona, los recursos petrolíferos; o intereses estratégicos, la contención de la Unión Soviética durante la Guerra Fría; o al virtual secuestro de la política exterior estadounidense por parte de un oscuro lobby al servicio de Israel apoyado incondicionalmente por la comunidad judía estadounidense. Todos estos factores, sin duda, han tenido su importancia en la evolución de la relación entre Estados Unidos e Israel, pero el origen y el desarrollo de esta relación son bastante más complejos que la mera influencia unilateral de uno de estos factores.

En este artículo se señalarán las pautas generales que han condicionado el origen y la evolución de esta relación dando una visión histórica que muestra que las relaciones entre ambos países no han sido siempre tan cercanas como en los últimos años. Tras esta introducción, nos centraremos en el papel que juegan los grupos de presión en el diseño y ejecución de la política exterior norteamericana en relación con el conflicto palestinoisraelí.

\section{BREVE PERSPECTIVA HISTÓRICA DE LAS RELACIONES ENTRE ESTADOS UNIDOS E ISRAEL Y ESTADOS UNIDOS Y EL PUEBLO PALESTINO}

La historia de las relaciones entre Estados Unidos e Israel se puede dividir en las siguientes fases: ${ }^{4}$

Primera fase (1948-1967): Tradicionalmente, el comienzo de las relaciones entre ambós países se fecha el 14 de mayo de 1948, cuando el presidente Truman tardó sólo 11 minutos en reconocer al nuevo Estado de Israel. Las razones de Truman, que actuó en contra de las recomendaciones del Departamento de Estado, entre otras voces que se oponían, todavía son objeto de debate. Sin embargo, es indiscutible que consideraciones de

británicos y estadounidenses en dicho país con el fin de poner en evidencia la incompetencia de los egipcios y forzar la permanencia de los británicos. El caso desembocó en la dimisión de Pinchas Lavon, Ministro de Defensa en 1955, al ser éste injustamente considerado responsable. En 1960 la verdad saldría a la luz consternando a la opinión pública israelí como si fuese un nuevo "caso Dreyfus". (Sachar, Howard Morley. A History of Israel : From the Rise of Zionism to Our Time. 2nd ed. New York: A.A. Knopf, 1996, 480-481, 543-547).

${ }^{3}$ El ataque se produjo el 8 de junio de 1967, posiblemente para evitar que el navío norteamericano interceptase las comunicaciones del ejército israelí durante la guerra árabo-israelí de 1967. (Smith, Charles D. Palestine and the Arab-Israeli Conflict. 3rd ed. New York: St. Martin's Press, 1996, 200).

\footnotetext{
${ }^{4}$ Basado en la periodización de Samuel Lewis, véase Lewis, Samuel W. "The United States and Israel: Evolution
} of an Unwritten Alliance." The Middle East Journal 53, nº 3 (1999): 364-78. 
tipo electoral fueron tomadas en cuenta por el Presidente. Paralelamente, Estados Unidos siguió manifestando su apoyo a los esfuerzos diplomáticos de Naciones Unidas por negociar una solución pacífica al conflicto árabo-israelí creado a raíz del establecimiento del Estado hebreo. La ayuda económica que recibe Israel en estos primeros años proviene en su mayor parte de la comunidad judía y de instituciones privadas con el objetivo de sufragar los gastos derivados de la absorción de inmigrantes. En cuanto a la asistencia militar, ésta proviene principalmente de Francia, pues a ambos países les une su enemistad hacia el nacionalismo árabe, sobre todo tras la crisis de Suez y el estallido de la guerra argelina contra la potencia colonial, que despierta las simpatías del mundo árabe y que recibe el apoyo del líder egipcio Gamal Abdel Naser. Así mismo, Francia proporcionará ayuda a Israel en el desarrollo de su capacidad nuclear de 1953 a $1964^{5}$.

Segunda fase (1967-1977): Durante los años sesenta Francia empieza a replantearse sus relaciones con el mundo árabe y opta por tomar una postura más moderada con respecto al conflicto árabo-israelí, actitud que cristaliza cuando estalla la Guerra de los Seis Días y De Gaulle pone fin definitivamente al suministro de armas francesas, dando lugar a que Estados Unidos emerja así como el sustituto de Francia en el abastecimiento de armas a Israel ${ }^{6}$.

En 1970 se desencadena la violencia en Jordania entre milicias palestinas y el ejército jordano. Durante la crisis del llamado Septiembre $\mathrm{Negro}^{7}$, y a causa de la asistencia militar que la Unión Soviética dispensa a Egipto, Israel emerge como un valioso aliado en el marco de la estrategia de contención de la influencia soviética en Oriente Medio ${ }^{8}$. Ello permite que Henry Kissinger ${ }^{9}$, Consejero de Seguridad Nacional del presidente Nixon (1969-1974), justifique reconsiderar las relaciones con Israel, comenzando así la relación de carácter "estratégico" entre ambos países. De esta manera, tras la Guerra del Yom Kippur (1973), Israel empieza a recibir parte de la ayuda militar estadounidense directa en vez de préstamos y en 1975 parte de la ayuda económica que anteriormente se destinaba a proyectos determinados pasa a ser concedida en forma de préstamos directos y en efectivo ${ }^{10}$.

Tercera fase (los años de Carter, 1977-1981): La política exterior del presidente Carter se caracterizó por su genuina preocupación por la defensa de los Derechos Humanos a escala internacional. Con respecto al conflicto árabo-israelí esto se tradujo en que Carter

${ }^{5}$ Lewis, 365-66; Sachar, 290, 311-312, 483, 877.

${ }^{6}$ Sachar, 569, 692-693.

${ }^{7}$ Ante la grave situación en Jordania, donde estalla una guerra civil entre la OLP y el Estado jordano, Estados Unidos teme que la Unión Soviética intervenga a través de Siria en favor de los palestinos, por lo que pide a Israel su colaboración y el Estado hebreo accede. Reforzado por el despliegue de la Sexta Flota estadounidense en el Mediterráneo oriental y del ejército israelí cerca de su frontera, el ejército jordano lanza una ofensiva que derrota a los sirios forzando su retirada. (Sachar, 687, 768-769; Smith 224).

${ }^{8}$ Sachar, 695-697.

${ }^{9}$ Consejero de Seguridad Nacional de 1969 a 1975 y Secretario de Estado de 1973 a 1977.

${ }^{10}$ Mark, Clyde R. "Israeli-United States Relations". CRS Issue Brief for Congress. Washington, D.C.: Congressional Research Service. The Library of Congress, 2001, 10-11. 
fuera el primer presidente de los Estados Unidos en hablar públicamente de los derechos de los palestinos y que promocionase una Declaración conjunta con la Unión Soviética al respecto. Además, el Presidente medió entre egipcios e israelíes en las negociaciones de Camp David (1978) que, finalmente, condujeron a la firma del primer acuerdo de paz entre Israel y un país árabe. A pesar de este éxito diplomático, Carter fracasó en su intento por solucionar la cuestión palestina dentro del marco de dichas negociaciones.

Cuarta fase (los años de Reagan, 1981-1989): La administración Reagan retoma con fuerza el discurso de la Guerra Fría basado en defender al "mundo libre" del comunismo internacional. En dicho contexto se enmarca un replanteamiento de las relaciones con Israel, un país que el nuevo Presidente considera como un "aliado leal, amistoso y democrático rodeado por un mar de Estados árabes hostiles, algunos de ellos aliados de la Unión Soviética" 11 . Por ello, a lo largo de la década de los ochenta se fortalece la relación estratégica con Israel, sobre todo durante el segundo mandato de Reagan cuando, por un lado, se firman acuerdos de carácter estratégico que sientan un importante precedente en las relaciones de ambos países y, por otro, la ayuda económica y militar estadounidense, que antes se concedía en forma de préstamos, a partir de este momento se desembolsa en su totalidad en efectivo. Es decir, los fondos ya no se tendrán que devolver ni irán destinados a ningún proyecto concreto. El buen momento del que disfrutan las relaciones entre ambos países favorece también al lobby pro-israelí que adquiere una fuerza sin precedentes ${ }^{12}$ y esto se verá reflejado en la publicación de obras denunciando los peligros la desmedida influencia política del lobby pro-israelí ${ }^{13}$.

Quinta fase (los años de Bush padre: 1989-1993) La caída del muro de Berlín en 1989 supone el fin de la Guerra Fría y del orden bipolar, lo que reafirma la influencia política y militar de Estados Unidos sin rival en la zona. Bush y su Secretario de Estado, James Baker, reconducen la política exterior estadounidense en favor de una solución negociada al conflicto Palestino-Israelí reconociendo que la ocupación y el expansionismo israelí son obstáculos para la paz. Así, tras la Guerra del Golfo de 1991, para recompensar la favorable actitud árabe y aprovechando la necesidad económica israelí para absorber la inmigración de judíoś de la ex Unión Soviética ${ }^{14}$, Bush consigue que se celebre la Conferencia de Madrid en octubre de 1991, en cuyo marco se llevan a cabo negociaciones directas de todas las partes implicadas: Israel con Líbano, Siria, Jordania y los palestinos.

Sexta fase (los años de Clinton: 1993-2001): Israel reconoce a los palestinos como "pueblo" cuando Isaac Rabin y Yaser Arafat intercambian cartas de mutuo reconocimiento el 10 de septiembre de 1993, tres días antes de firmar la Declaración de Principios. Aquel mismo día, Estados Unidos anuncia que resumirá sus contactos con la OLP, que desde 1984 había sido ilegal por iniciativa del Congreso. De esta manera comienza todo un periodo de

\footnotetext{
${ }^{11}$ Lewis, 368-369.
}

${ }^{12}$ Reagan incluso denomina a AIPAC como “compañero". Neff, Donald. Fallen Pillars : U.S. Policy Towards Palestine and Israel since 1945. Washington, D.C.: Institute for Palestine Studies, 1995, 124.

${ }^{13}$ Véase Findley, Paul. They Dare to Speak Out: People and Institutions Confront Israel's Lobby. Westport, Connecticut: Lawrence Hill \& Company, 1985.

${ }^{14}$ El presidente Bush presiona al gobierno israelí reteniendo los avales de los préstamos que éste necesita. 
negociaciones a lo largo de 1993-1999 que, obstaculizadas en gran medida por el gobierno de Benjamín Netanyahu, finalmente se resuelve con el fracaso del presidente Clinton por alcanzar un acuerdo.

Las relaciones de Estados Unidos con los palestinos también han evolucionado de manera significativa, como se explica a continuación ${ }^{15}$ :

Primera fase (1948-1974): Para el gobierno y la opinión pública estadounidense, antes de la guerra de 1948 el palestino "no existe", pero tras ella emerge la imagen del palestino como "refugiado". Es decir, para Washington la cuestión palestina se trata de un problema humanitario, no de un problema político. Años después, y como consecuencia de la Guerra de los Seis Días de 1967, surge la figura del palestino como un civil bajo ocupación militar, pero también, a raíz de las acciones terroristas cometidas por elementos radicales, a partir de 1968 se identificará con la del terrorista.

Segunda fase: En 1975, tras el fin de la guerra de 1973 y la primera gran crisis del petróleo, se produce un punto de inflexión al reconocer el Departamento de Estado ante el Congreso estadounidense que el problema de fondo del conflicto árabo-israelí es la cuestión palestina. Aunque Estados Unidos no cambia sustancialmente su política exterior, esto supone el reconocimiento de la existencia del pueblo palestino y sienta las bases para la posterior iniciativa diplomática del presidente Carter, quien intentará incluir el problema palestino en las negociaciones conducentes a la firma de los acuerdos de Camp David (1978-1979), pero sin éxito.

Tercera fase: Durante la década de los ochenta, el Congreso aprueba leyes que prohíben negociar con representantes de la Organización para la Liberación de Palestina (OLP) hasta que esta organización aceptase las resoluciones del Consejo de Seguridad de Naciones Unidas 242, 338 y renunciase al terrorismo. Estas condiciones se cumplieron en noviembre de 1988, casi un año después del estallido de la primera Intifada. El Ejecutivo, entonces, se muestra favorable a establecer contactos con OLP, pero el Congreso estadounidense se mantiene escéptico. De hecho, esto no es más que un ejemplo más de cómo el Congreso, por lo general, no facilita las relaciones entre Estados Unidos y los palestinos.

Cuarta fase: Durante la década de los noventa, tanto Clinton como Bush se han mostrado favorables al establecimiento de un Estado palestino, lo cual supone un cambio significativo si recordamos que con anterioridad a los últimos días de Clinton, Estados Unidos no apoyaba el derecho a la independencia o a un Estado de los Palestinos, sino que se barajaba la posibilidad de una confederación de algún tipo con Jordania. En este contexto, la visita de Clinton a los territorios ocupados en diciembre de 1998 tuvo cierta importancia simbólica.

Sin embargo, y a pesar de los gestos de estos presidentes, la política exterior estadounidense seguía sin rectificar su parcialidad a favor de Israel como muestra la postura norteamericana hacia dos cuestiones de suma importancia para los palestinos como son el derecho al retorno de los refugiados y el estatuto de Jerusalén. 
En cuanto a la cuestión de los refugiados, no fue hasta 1992 que la administración Bush apoyó abiertamente la Resolución de la Asamblea General de Naciones Unidas 194 del 11 de diciembre de 1948, en la que, con ánimo de resolver la cuestión palestina, Naciones Unidas defendía que los refugiados pudiesen volver a sus hogares y, si elegían no hacerlo, que fuesen compensados ${ }^{16}$. Aun así, el derecho de los refugiados al retorno a sus hogares se ha utilizado posteriormente como elemento de negociación durante el llamado "proceso de paz" con el ánimo de que los palestinos limitasen en gran medida dicho retorno o que incluso acabaran por abandonar sus aspiraciones a volver a los territorios de donde fueron expulsados.

Con respecto a Jerusalén, el Congreso se ha mostrado favorable al traslado de la Embajada norteamericana de Tel Aviv a Jerusalén, lo que representaría el reconocimiento de Jerusalén como capital del Estado israelí, violando la ley internacional que considera a esta ciudad corpus separatus, menos Jerusalén Este que se considera "territorio ocupado" desde 1967. En 1995 el Congreso tramitó al respecto la ley denominada Jerusalem Embassy Act que el Presidente Clinton ratificó y que determinaba que si se incumplía lo propuesto por el Congreso y el traslado no se realizaba antes del 31 de mayo de 1999 se recortaría el presupuesto del Departamento de Estado para la adquisición y mantenimiento de Edificios en el Extranjero en un 50 \%. Paradójicamente, la ley también establece que el gobierno puede retrasar dicho traslado por un periodo de seis meses por razones de "seguridad nacional", que es lo que han venido haciendo los presidentes Clinton y Bush desde entonces ${ }^{17}$.

\section{LA POLÍTICA ESTADOUNIDENSE TRADUCIDA A CIFRAS ECONÓMICAS}

A continuación y a modo de sumario señalaremos las principales características de la asistencia económica y militar que Israel recibe de Estados Unidos, la cual muy superior en cantidad y calidad a la que es suministrada a otros Estados, así como la ayuda que, por su parte, reciben los palestinos. Dada la complejidad del diseño financiero de los fondos destinados a Israel este resumen no es exhaustivo, pero pensamos que será suficiente para ofrecer al lector una idea general de los beneficios que reporta al gobierno israelí su especial relación con Washington.

En los últimos veinte años, la ayuda estadounidense directa anual a Israel ha estado alrededor de los tres mil o tres mil quinientos millones de dólares (el 60\% para fines

\footnotetext{
${ }^{16}$ Elgindy, Khaled. "Overview on U.S. policy toward Israel and the Occupied Territories". 26 de octubre de 2001. Manuscrito consultado por gentileza del autor. Neff, 126. Fragmento de la versión inglesa de dicha resolución: “...Resolves that the refugees wishing to return to their homes and live at peace with their neigbours should be permitteed to do so at the earlist practicable date, and that compensation should be apid for the property of those choosing not to return and for loss of or damage to property which, under principles of international law or in equity, should be made good by the Governments or authorities responsible;...". Reich, Bernard, ed. Arab-Israeli Conflict and Conciliation: A Documentary History. Westport: Praeger Publishers, 1995, p. 80.

${ }^{17}$ Elgindy, Khaled. "Overview on U.S. policy toward Israel and the Occupied Territories"; Mark, Clyde R., "Jerusalem: The U.S. Embassy and P.L. 104-45", CRS Report for Congress. Washington, D.C.: Congressional Research Service. The Library of Congress, 22 de septiembre de 1999; Mark, Clyde R., "Israeli-United States Relations", CRS Issue Brief for Congress. Washington, D.C.: Congressional Research Service. The Library of Congress, actualizado el 23 de mayo de 2001, 6; Mark, Clyde R., "Palestinians and Middle East Peace: Issues for the United States", CRS Issue Brief for Congress. Washington, D.C.: Congressional Research Service. The Library of Congress, actualizado el 23 de mayo de 2001, 7-8.
} 
militares y el $40 \%$ restante para fines civiles). Las condiciones para el recibo de esta ayuda son especialmente beneficiosas para Israel ya que, al contrario de lo que ocurre en relación con otros países recipientes de ayuda estadounidense, desde mediados de los años 80 la totalidad de la ayuda exterior destinada a Israel se transfiere directamente, sin limitaciones sobre cómo debe ser empleada, y se abona durante el primer mes del año fiscal en vez de en tres o cuatro plazos distribuidos a lo largo del año ${ }^{18}$. Parte de esta ayuda se destina, por ejemplo, a sufragar los gastos correspondientes a la recepción y asentamiento de las recientes olas de inmigración de judíos de la antigua Unión Soviética. A este fin se han destinado una media de unos ochenta millones de dólares al año desde 1992 para financiar viviendas, infraestructuras y creación de empleo para estos nuevos ciudadanos israelíes ${ }^{19}$.

Además de esta ayuda de origen gubernamental, se estima que Israel también cuenta anualmente con unos mil millones de dólares en donaciones de carácter filantrópico por parte de ciudadanos estadounidenses, una cantidad equivalente en créditos comerciales a corto y largo plazo y otros mil millones aproximadamente en ingresos por venta de bonos israelíes ${ }^{20}$. Por lo tanto, la cantidad total estimada de fondos de origen estadounidense de la que se benefician seis millones de israelíes es de unos cinco mil millones de dólares anuales.

Es digno de señalar así mismo que parte de la ayuda destinada a Israel es objeto de controversia puesto que algunos consideran que viola las propias leyes estadounidenses, aunque el Congreso nunca ha querido investigar esto a conciencia. Estas leyes prescriben que la ayuda militar debe ser utilizada sólo en defensa propia, prohíben ayuda a Estados que de manera reiterada comentan violaciones de derechos humanos y también prohíben que un país receptor de ayuda militar venda a terceros países tecnología militar cedida por los Estados Unidos, como se sospecha que ha ocurrido con Israel y sus supuestas ventas de armas a Irán, países de Iberoamérica y China ${ }^{21}$.

En cuanto al pueblo palestino, el nivel de ayuda es más precario. Tras la firma de la Declaración de Principios en 1993, la administración Clinton ofreció quinientos millones de dólares para impulsar el desarrollo económico de Cisjordania y Gaza por un periodo de cinco años. En 1998, y de manera complementaria, el Acuerdo de Wye River destinaba cuatrocientos millones de dólares a lo largo de tres años (la tercera parte de lo que recibiría Israel por el mismo motivo). Sin embargo, a la hora de la verdad las recomendaciones del Presidente sólo se traducen en partidas presupuestarias con el apoyo del Congreso, y es ahí donde en el mejor de los casos se retrasan y obstaculizan las ayudas destinadas a los palestinos. Además, éstas nunca puede ser directa, al contrario que en el caso de Israel, porque en mayo de 2000 el Congreso legisló que las ayudas serían gestionadas a través del Banco Mundial, de USAID (Agencia Estadounidense para el Desarrollo Internacional) o de

\footnotetext{
${ }^{18}$ Mark, Clyde R., "Israeli-United States Relations", 10-11; Mark, Clyde R., "Israel: U.S. Foreign Assistance", CRS Issue Brief for Congress. Washington, D.C.: Congressional Research Service. The Library of Congress, actualizado el 23 de mayo de 2001, 8-9, 14-15.

${ }^{19}$ Mark, Clyde R., "Israel: U.S. Foreign Assistance", 3-4, 15.

${ }^{20}$ Mark, Clyde R., "Israel: U.S. Foreign Assistance", Summary, p. 0.

${ }^{21}$ Mark, Clyde R., "Israeli-United States Relations", 9-12; MIFTAH, "US foreign aid to Israel", 20 de mayo de 2002. Disponible en <http://www.miftah.org/Display.cfm?Docld=753\&Categoryld=4>.
} 
distintas Organizaciones No Gubernamentales. En la práctica, desde el año fiscal 1995, Estados Unidos ha venido suministrando una media de setenta y cinco millones de dólares anuales ${ }^{22}$.

La única ayuda constante que han recibido los palestinos es la contribución que hace Estados Unidos al presupuesto anual de UNRWA (Organismo de Asistencia de Naciones Unidas para los Refugiados Palestinos), estimada alrededor del $30 \%$ del presupuesto total de UNRWA desde sus inicios en 1950.23 Esta Agencia proporciona educación, asistencia sanitaria, formación profesional, servicios sociales, etc. a los tres millones novecientos mil refugiados palestinos que tiene registrados en la actualidad. Según UNRWA, durante el año 2001 Estados Unidos contribuyó con 122,781,340 dólares ${ }^{24}$, cantidad que añadida a la ayuda exterior destinada a los palestinos supone un total de 197 millones de dólares aproximadamente para dicho año. Una cifra muy inferior a la recibida anualmente por los israelíes.

\section{LOS GRUPOS DE PRESIÓN ESTADOUNIDENSES O LOBBIES}

El proceso de diseño y ejecución de una política exterior es complejo y en él influyen diversos elementos, siendo uno de ellos el papel que desarrollan los grupos de presión, de interés o "lobbies".

El sistema político estadounidense permite que la sociedad participe en el gobierno de su nación. Esta participación ciudadana se puede canalizar a través de elecciones, presidenciales o legislativas, encuestas de opinión, etc. Sin embargo, el sistema político estadounidense, además, es especialmente abierto permitiendo la acción de otros agentes y poderes, no sólo el ejecutivo, en la elaboración de su política exterior.

La base legal que permite el establecimiento y acción de los grupos de presión la otorga la Declaración de Derechos norteamericana, Bill of Rights, que en su Artículo Uno reconoce el derecho del ciudadano a "pedir al gobierno la reparación de agravios"25, instituyendo así una vía de acceso al ejecutivo y al legislativo gracias a la cual el ciudadano que lo desee puede expresar su opinión o preocupación sobre un determinado asunto a sus representantes electos ${ }^{26}$.

Estos grupos de presión son, pues, el resultado de la organización y el activismo político de ciertos individuos con intereses comunes, los cuales identifican al grupo y pueden ser de muy diversa índole, pudiendo representar intereses empresariales, es el caso de ciertas industrias como las tabacaleras; o ético-morales, como en el caso de los grupos a favor y en

${ }^{22}$ Mark, Clyde R., "Palestinians and Middle East Peace: Issues for the United States", 3-4.

${ }^{23}$ BADIL Resource Center, "Israel's Military Campaign and International Assistance: Paying for a Climate of Impunity”, 18 de abril de 2002. Disponible en <http://www.badil.org/Press/2002/press246-02.htm>.

${ }^{24}$ External Relations Department, UNRWA Headquarters, Gaza, "Pledges and contributions to UNRWA (cash and in kind) for 2001 by country and fund (in US dollars) as at 31 december 2001", 1 marzo de 2002. Disponible en $<$ http://www.un.org/unrwa/finances/cont-june01.htm>.

25 "Congress shall make no law ... to petition the government for redress of grievances" citado por Khoury, Nabeel A. "The Arab Lobby: Problems and Prospects." The Middle East Journal 41, nº 3 (1987), 379.

${ }^{26}$ Mc Mathias Jr., Charles. "Ethnic Groups and Foreign Policy." Foreign Affairs 59, nº 5 (1980-1981), 979. 
contra de la legalización del aborto (pro-life y pro-choice). En cuanto a los intereses de otros grupos étnicos, además del judío y el árabe, también han presionado a los gobernantes estadounidenses en determinados momentos lobbies como el irlandés, el griego o el turco ${ }^{27}$.

Concretamente, Israel y la defensa de su privilegiada relación con Estados Unidos son apoyados por distintos grupos, de los cuales el más significativo y al que muchos se refieren como 'el lobby' es AIPAC, siglas inglesas de Comité de Asuntos Públicos Americano-Israelí, fundado en 1948 como sucesor de la oficina pro-sionista en Washington y que se enorgullece de ser "la organización que más influye en la relación de Estados Unidos con Israel"28, título concedido por el diario The Washington Post.

¿Cómo actúa AIPAC? AIPAC, oficialmente, realiza una función informativa y movilizadora de organizaciones afines: publica una revista informativa sobre Israel y Oriente Medio, ofrece información de manera inmediata a los medios de comunicación y a congresistas, moviliza a sus miembros y simpatizantes cuando lo ve necésario facilitando el contacto de los electores con sus representantes en el Congreso a través de correspondencia, llamadas de teléfono, correos electrónicos, etc. ${ }^{29}$.

En principio, esta línea de actuación no es muy distinta a la de otros lobbies y aunque sus recursos económicos y su nivel organizativo son extraordinarios, por sí solos éstos no explican satisfactoriamente la inmensa influencia política de la que disfruta la organización pro-israelí. La respuesta a esta pregunta hay que buscarla también en el diseño del sistema político estadounidense y, particularmente, en el sistema electoral y en los medios que los candidatos emplean en la recaudación de fondos necesarios para llevar a cabo una campaña electoral con probabilidades de éxito.

\section{FINANCIACIÓN ELECTORAL Y AIPAC}

Oficialmente, al ser una organización que "ejerce presión", a AlPAC no le está permitido hacer contribuciones electorales. Para esto están las PAC, siglas inglesas de Comités de Acción Política, que son las organizaciones que legalmente canalizan los fondos de aquellos ciudadanos que quieren contribuír económicamente en la campaña de un cierto candidato. Suelen representar intereses industriales, ideológicos o sindicales y no pueden sobrepasar ciertas cantidades: 5.000 dólares por candidato y elección, 15.000 dólares por año y partido o 5.000 dólares si el destinatario es otra PAC $^{30}$. Paralelamente es posible contribuir a título individual, con un límite de 1.000 dólares por candidato y elección o 20.000 por año si el receptor es un partido político. Por último, hasta 2002 ha existido el llamado "soft money", que se trata de una modalidad de contribución sin límite estipulado y que realizan particulares a partidos políticos para sufragar gastos

\footnotetext{
${ }^{27}$ Mc Mathias, 982-987. la organización <http://www.aipac.org/>.

${ }^{29}$ Mc Mathias, 993.

${ }^{30}$ The Center for Responsive Politics: "What is a PAC?". Disponible en $<$ http://www.opensecrets.org/pacs/pacfaq.asp >.
}

28 "The most important organization affecting America's relationship with Israel". Véase la página en Internet de 
$\operatorname{organizativos}^{31}$. En principio no está permitido que el contribuyente especifique a qué fin exactamente debe ir destinada su donación, pero en la práctica se sospecha que esto ocurría. El abuso del "soft money" ha llegado a alcanzar cifras astronómicas, por lo que finalmente, tras las elecciones de 2002, se ha reformado el sistema de financiación de las campañas electorales prohibiéndose esta modalidad. Sin embargo, este es un tema controvertido pues algunos opinan que aunque el "soft money" desaparezca como tal, los interesados encontrarán otros cauces para canalizar fondos destinados a determinados intereses políticos $^{32}$.

Esta somera explicación sobre la financiación de las campañas electorales es pertinente porque, junto a la cantidad y calidad de la ayuda estadounidense a Israel, es uno de los pilares que sustentan la influencia política que ejercen los grupos pro-israelíes en el sistema político norteamericano. Como hemos mencionado antes, AIPAC no puede contribuir económicamente en la campaña de ningún candidato, pero sí puede, y de manera muy efectiva, movilizar a sus miembros, simpatizantes y, sobre todo, a multitud de PACs asociadas a AIPAC. De manera que la actuación de AIPAC puede ser decisiva en el resultado de una campaña electoral, y de hecho lo es. Ya en los años ochenta hubo un par de casos que llamaron mucho la atención a este respecto, e incluso uno de los candidatos que finalmente fue derrotado, Paul Findley, gracias al apoyo que AIPAC ofreció a su oponente, escribió un libro denunciando el efecto negativo que la influencia de AIPAC causaba al impedir cualquier debate o discusión que cuestionase la política israelí o las relaciones entre Estados Unidos e Israel ${ }^{33}$.

\section{LAS ELECCIONES LEGISLATIVAS DE 2002}

El proceso electoral que se celebra a lo largo de 2002 ha hecho resurgir la cuestión del "efecto AIPAC", al ser éste un año de elecciones parciales, a mitad del mandato presidencial, que se celebraron el 5 de noviembre y por las que se renovó la Cámara de Representantes y un tercio del Senado. Las elecciones primarias para elegir a los candidatos por cada partido político en cada distrito electoral tuvieron lugar en los meses previos, periodo durante el cual se dieron dos casos muy significativos en los cuales el "efecto" AIPAC marcó la diferencia.

Earl Hilliard, candidato demócrata por Alabama, y Cynthia MacKinney, candidata demócrata por Georgia, ambos congresistas desde 1992, perdieron sus escaños en la Cámara de Representantes ante sus respectivos adversarios a causa del apoyo de contribuyentes movilizados por el lobby pro-israelí. Algunas organizaciones árabes y musulmanas se movilizaron en apoyo de Hilliard y MacKinney para contrarrestar las altas

${ }^{31}$ Makinson, Larry: "The Old Soft Money Ain't What It Used to Be", The Center for Responsive Politics. Disponible en <http://www.opensecrets.org/newsletter/ce74/softmoney.asp>.

${ }^{32}$ Véase Bailey, Holly: "Shadow Dancing: A Look at the Groups Who Want to Keep Soft Money Flowing". Disponible en <http://www.opensecrets.org/alerts/v6/alertv6_67.asp>, 25 de noviembre de 2002.

${ }^{33}$ Véase Findley, Paul. They Dare to Speak Out : People and Institutions Confront Israel's Lobby. El autor y excongresista republicano por el Estado de Illinois de 1963 a 1981 dirige en la actualidad el Consejo por el Interés Nacional (Council for the National Interest), una organización que presiona en apoyo de una política exterior neutral en relación a Oriente Medio. Véase <http://www.cnionline.org/>. 
cantidades recaudadas por los pro-israelíes, pero su capacidad de respuesta no pudo llegar al nivel que se hubiera requerido para evitar ambas derrotas.

En el caso de Hilliard, candidato por el económicamente deprimido séptimo distrito electoral de Alabama, los vastos recursos de su oponente le permitieron emitir anuncios en la televisión local que cuestionaban la posición del representante con respecto a Oriente Medio e insinuando supuestas conexiones con el terrorismo.

¿Cuáles fueron los pecados de Hilliard? Sus críticos denunciaron su apoyo a la creación de un Estado palestino, su oposición a una resolución del congreso en apoyo de Israel en su así llamada "guerra contra el terror" y su viaje a Libia en 1997. Su contrincante, Artur Davis, consiguió reunir un $50 \%$ más de financiación, siendo el $88 \%$ del cual proveniente de contribuciones individuales ${ }^{34}$ y el $82 \%$ del total provenientes de donantes no residentes en Alabama. Las comunidades árabe y musulmana estadounidenses reaccionaron y así Hilliard consiguió el $68 \%$ de sus fondos de fuera del Estado, pero no fue suficiente, los recursos de Davis le permitieron lanzar una campaña televisiva de desprestigio que, algunos mantienen, causó la derrota al representante ${ }^{35}$.

Las derrotas de MacKinney ${ }^{36}$ y Hilliard, ambos con experiencia y provenientes de Estados sureños cuya población se muestra normalmente muy al margen de cuestiones de política exterior relacionada con Oriente Medio, exponen con claridad cómo funciona en la práctica la conexión entre el lobby pro-israelí y la financiación de campañas electorales y como esto afecta al diseño del congreso estadounidense. A pesar de que el esfuerzo realizado por las comunidades árabe y musulmana finalmente fracasara, algunos activistas argumentan que este episodio ha supuesto el reconocimiento por parte de los medios de

\footnotetext{
${ }^{34}$ The Center for Responsive Politics, "Earl Hilliard: 2002 Politician Profile". Disponible en <http://www.opensecrets.org/politicians/summary.asp?CID=N00003008\&cycle=2002>; The Center for Responsive Politics, Total Raised and Spent 2002 RACE: ALABAMADISTRICT 7. Disponible en $<$ http://www.opensecrets.org/races/summary.asp?ID=AL07\&Cycle=2002>.

${ }^{35}$ Foxnews. "Hilliard: Mideast Dispute Takes Toll on Black-Jewish Relations" [Internet]. Foxnews, 28 de junio de 2002. Disponible en <http://www.foxnews.com/story/0,2933,56523,00.html>; Frank, Mitch. "The Middle East - in Alabama? Post-9/11 Politics Takes on a New Twist in Alabama's 7th Congressional District". [Internet]. Time, 29 de junio de 2002. Disponible en <http://www.time.com/time/columnist/frank/article/0,9565,267696,00.html>; Schneider, Bill. "Voters Send a Message in Alabama. In 1997, Democratic Congressman Earl Hilliard Angered Supporters of Israel When He Traveled to Libya". [Internet]. CNN, 1 de julio de 2002. Disponible en $<$ http://www.cnn.com/2002/ALLPOLITICS/07/01/pol.play.israel>.
}

${ }^{36}$ Sobre el caso de Cynthia MacKinney véase Edsall, Thomas B. "Muslims Aid Embattled House Member. Lawmaker Opposed Pro-Israel Resolution; Rival Backed by Jewish Leaders”. [Internet]. The Washington Post, 2 de agosto de 2002, pág. A06. Disponible en <http://www.washingtonpost.com/wp-dyn/articles/A340222002Aug1.html>; Eilperin, Juliet. "In Minnesota, U.S. House Campaigns Become Battleground for Spy Vs. Spy". [Internet]. The Washington Post, 12 de agosto 2002, pág. A04. Disponible en <http://www.washingtonpost.com/wp-dyn/articles/A6439-2002Aug11.html>; Eversley, Melanie. "Arab-American Dollars Shore up Mckinney”. [Internet]. The Atlanta - Journal Constitution, 22 de junio de 2002. Disponible en $<$ http://www.accessatlanta.com/ajc/metro/0602/22mckinney.html>; Torpy, Bill. "Majette's Campaign Coffers Top Mckinney's". [Internet]. The Atlanta Journal - Constitution, 13 de agosto de 2002. Disponible en <http://www.accessatlanta.com/ajc/metro/0802/11fourthdistrict.html>; Washington Post Staff Writer. "Mideast Fuels 2 Democratic Primaries. Longtime House Incumbents Face Fierce Opposition Because of Their Views". [Internet]. The Washington Post, 6 de junio de 2002, página A02. Disponible en <http://www.washingtonpost.com/ac2/wp-dyn?pagename=article \&node=\&contentId=A2382 
comunicación de la movilización de estas comunidades como un factor a tener en cuenta en próximas contiendas electorales ${ }^{37}$.

\section{ACTIVISMO DE LAS COMUNIDADES ÁRABE Y MUSULMANA}

Algunos califican de "lobby" a este activismo por parte de organizaciones árabes y musulmanas que en los últimos años ha empezado a hacerse notar. Aunque éstas no disfrutan de la influencia política del pro-israelí, lo cierto es que el "lobby árabe" mantiene una lenta pero constante progresión dentro del sistema político norteamericano ${ }^{38}$.

El activismo político de la comunidad árabo-americana surge en el marco del movimiento por los derechos civiles de los años sesenta, y su desarrollo tuvo como punto de inflexión en este estadio inicial la guerra de 1967 y la campaña de difamación contra los árabes durante la crisis del petróleo ${ }^{39}$.

Las principales organizaciones de árabes estadounidenses son:

NAAA, National Association of Arab-Americans (Asociación Nacional de ÁraboAmericanos), creada en 1972 para presionar "por una política norteamericana hacia Oriente Medio constructiva" y de tendencia republicana cercana a la parte de la comunidad integrada por hombres de negocio y con una posición económica elevada ${ }^{40}$.

ADC, Anti-Discrimination Committee (Comité anti-Discriminación), fundado en 1980 por James Aburezq, ex-Senador, con el objetivo de luchar contra prejuicios y estereotipos anti-árabes, de tendencia demócrata, atrae en general el apoyo de la clase media y mediabaja ${ }^{41}$.

AAI, Arab-American Institute (Instituto Árabe-Americano), dirigido por James Zogby, su objetivo principal es conseguir la implicación de la comunidad en la escena política estadounidense.

A pesar de la existencia de estas organizaciones, el poder de ambos lobbys difícilmente se puede comparar. AIPAC gestiona recursos económicos muy superiores y su sofisticada organización y el activismo de la comunidad judía, ayudado por su concentración estratégica en determinadas zonas de los Estados Unidos, ${ }^{42}$ le permite un gran poder de respuesta ante la realidad política del momento. Por el contrario, el lobby árabe se enfrenta a fundamentales problemas internos que perjudican seriamente su efectividad.

\footnotetext{
${ }^{37}$ Entrevista personal con Margaret Zaknoen, Director of Programs de la organización Musulmanes Estadounidenses por Jerusalén, realizada el 17 de septiembre de 2002 en Washington, D.C. (Estados Unidos).

${ }^{38}$ Idem.

${ }^{39}$ Shain, Yossi. "Arab-Americans at a Crossroads." Journal of Palestine Studies 25, $\mathrm{n}^{\circ} 3$ (1996), 47. Con posterioridad también han influido la Guerra del Líbano y las masacres de Sabra y Shatila en 1982. (Khoury, 392).

${ }^{40}$ Khoury, 381-383.

${ }^{41}$ Ibidem.

${ }^{42}$ Idem, 380.
} 
Primero, el problema básico al que se enfrentan es que gran parte de la comunidad árabe se compone de inmigrantes provenientes de países no democráticos donde, no sólo no se anima sino que se reprime duramente cualquier intento de participación política ciudadana, lo que determina, en el mejor de los casos, la aparición de una actitud general de 'apatía política ${ }^{43}$. Por ello, el principal objetivo de algunas de estas organizaciones es el de informar a la comunidad, de educarla sobre cómo funciona el sistema político estadounidense para hacerles entender la importancia de su propio activismo a la hora de influenciar la política exterior del país en el que viven. Este es el caso del Instituto AraboAmericano o de Musulmanes Estadounidenses por Jerusalén, por ejemplo. Una consecuencia inmediata de este déficit de activismo político es la escasez de recursos con la que se enfrentan estas organizaciones, pues tanto los fondos de que disponen como el número de miembros son limitados ${ }^{44}$, lo que lógicamente constriñe bastante su margen de maniobra, más aún si tenemos en cuenta los vastos recursos de su competidor pro-israelí.

Segundo, a la comunidad le cuesta integrarse con normalidad en la sociedad estadounidense al verse cohibidos por prejuicios y estereotipos anti-árabes muy comunes en los medios de comunicación y de entretenimiento norteamericanos. Con el objetivo de luchar contra la imagen estereotipada y los prejuicios contra todo lo árabe y lo musulmán, fue creado el Comité Anti-Discriminación en 1980 por James Aburezq, ex-Senador por Dakota del Sur. Desgraciadamente, la profusión del discurso anti-árabe y anti-musulmán, como explicamos más adelante, ha empeorado de manera muy significativa tras los atentados terroristas del 11 de Septiembre de 2001.

Tercero, el potencial de ambas comunidades para actuar de manera conjunta apenas se ha explotado, pues les cuesta mantener su cohesión debido a la diversidad nacional y religiosa de los que la integran, por una parte, y la diversidad de objetivos que guían las distintas organizaciones, por otra. Como ilustración, mencionaremos que la comunidad árabe en la actualidad se estima en tres millones de ciudadanos y es mayoritariamente cristiana: el $42 \%$ son católicos, el $23 \%$ ortodoxos y el $12 \%$ son protestantes, frente al $23 \%$ de musulmanes ${ }^{45}$. Este grupo poblacional surge como resultado de distintas olas de inmigración hacia Estados Unidos desde finales del siglo XIX. El flujo migratorio que se produce a finales del XIX y principios del XX se compone fundamentalmente de sirolibaneses que escapan de las duras circunstancias económicas que sufre su región de origen. Estos inmigrantes tienden a asimilarse en su sociedad de acogida y a no reivindicar su etnicidad árabe ${ }^{46}$. Posteriormente, los grupos de inmigrantes que llegan durante la segunda mitad del siglo XX vienen de sus países influenciados por corrientes nacionalistas siendo, por tanto, más conscientes de su arabidad que sus antecesores, a la vez que se ven expuestos a la lucha por los derechos civiles que tiene lugar en Estados Unidos liderada por

\footnotetext{
${ }^{43}$ Idem, 386.
}

${ }^{44}$ Entrevista personal con Margaret Zaknoen; Shain, 55.

45 Según estimaciones del Arab American Institute, Zogby International, Febrero de 2000. Disponible en $<$ http://www.aaiusa.org/demographics.htm>.

${ }^{46}$ Sobre estas primeras olas de inmigración de población árabe a Estados Unidos véase Suleiman, Michel W. “Arab Inmigrants to America, 1880-1940”. Awraq XVI (1995): 67-85. 
la comunidad afroamericana durante la década de los sesenta. Aún así, la escasa capacidad movilizadora de la comunidad impide que ésta represente un papel político efectivo ${ }^{47}$.

En la actualidad, las jóvenes generaciones que han nacido en Estados Unidos, se han educado allí y han participado desde temprana edad en el sistema político estadounidense tienden a expresar un cierto sentimiento de frustración a causa de la incapacidad e ineficacia mostrada por el tradicional liderazgo de la comunidad, criticando su falta de visión y entendimiento del sistema político que, al contrario que éste, AIPAC domina y de ahí el secreto de su éxito. Estos jóvenes activistas están convencidos de que la sociedad estadounidense es genuinamente más neutral que el Congreso en relación a la política exterior de su país y que numerosos congresistas actuarían de manera muy diferente si se sintiesen respaldados ante AIPAC por unas comunidades árabe y musulmana activas políticamente y de sólida organización ${ }^{48}$.

\section{EL COMPROMISO DE LA SOCIEDAD ESTADOUNIDENSE CON ISRAEL}

A pesar de todo lo expuesto anteriormente, la influencia política que pueda ejercer AIPAC no explica por sí sola el comportamiento estadounidense en sus relaciones con el exterior, pues los esfuerzos de AIPAC serían mucho menos fructíferos sin el genuino compromiso de la sociedad estadounidense con la supervivencia del Estado de Israel.

El origen y los fundamentos de la actitud pro-israelí de la sociedad estadounidense han sido el objeto de estudio de numerosas obras y los estudiosos del tema han identificado_las causas de este fenómeno. Principalmente éstas se pueden resumir en la percibida afinidad cultural y religiosa entre las sociedades israelí y estadounidense en conjunción con una profunda ignorancia acerca de la historia de los árabes y la región de Oriente Medio, una circunstancia que, como bien explica Kathleen Christison, los árabes no han sabido contrarrestar a la hora de comunicar a la opinión pública su versión del conflicto áraboisraelí, dejando así un vacío informativo del que los activistas pro-israelíes han sabido sacar partido ${ }^{49}$.

Por otro lado, la percepción que la comunidad judía en Estados Unidos tiene de sí misma es otro elemento fundamental que ayuda a entender su posicionamiento. Como Goldberg argumenta, a pesar de que los judíos estadounidenses ejercen una influencia desproporcionada con relación al segmento de la población que representan y que ésta se ve favorecida por su activismo cívico, vocación filantrópica y solidaridad interna ${ }^{50}$, en el seno de la comunidad judía perdura el mito forjado durante los siglos de la Diáspora de que el judío es un ser indefenso, que no es dueño de su propio destino y que, por tanto, se encuentra a merced de terceros. Es decir, los judíos estadounidenses, en general, no son del todo conscientes de su peso político, no perciben tener el poder que en realidad tienen. Esta

\footnotetext{
${ }^{47}$ Khoury, 385-386; Shain 48.
}

${ }^{48}$ Entrevista personal con Margaret Zaknoen; entrevista personal con Khaled Elgindy, Democratic Professional Staff Member en el Subcomité para Operaciones Internacionales y Derechos Humanos del Congreso de Estados Unidos, realizada el 19 de septiembre de 2002 en Washington, D.C. (Estados Unidos).

\footnotetext{
${ }^{49}$ Véase Christison, Kathleen. Perceptions of Palestine : Their Influence on U.S. Middle East Policy. Berkeley: University of California Press, 1999.

${ }^{50}$ Goldberg, J. J. Jewish Power : Inside the American Jewish Establishment. Reading, Mass.: Addison-Wesley, 1996, 14.
} 
permanente percepción de impotencia determina la persistencia de su discurso victimista, aunque para el observador externo esto sea realmente irónico.

Estas circunstancias y procesos socio-culturales e ideológicos han conformado el marco de referencia centrado en la versión israelí del conflicto que determina la política exterior estadounidense con respecto a Israel y Palestina. Para contrarrestar esta perspectiva parcial fundamentada en percepciones excluyentes de sí mismo y del otro sólo hay una opción de futuro y es la de fomentar el activismo político de los ciudadanos, y no sólo el de los árabes y los musulmanes estadounidenses, a favor de un mejor conocimiento sobre el mundo árabe que conduzca a la eliminación de las imágenes negativas que predominan sobre éste y una política exterior más equilibrada.

\section{TRAS EL 11 DE SEPTIEMBRE DE 2001}

A principios de 2001, la administración Bush ya incluía importantes elementos ultraconservadores $^{51}$ que defienden una postura en materia de política exterior de marcado carácter unilateralista, oponiéndose a lo que ellos conciben como las limitaciones que el sistema de derecho internacional impone a los intereses nacionales estadounidenses, a sus aspiraciones de hegemonía militar y económica global.

En este contexto, los ataques terroristas contra Nueva York y Washington DC reafirmaron en sus argumentos a los defensores del unilateralismo hegemónico, reforzando su postura desdeñosa con el sistema legal internacional que favorece el consenso y la acción concertada entre países a escala global. De manera que, estos objetivos políticos, reforzados por intereses económicos (algunos de los miembros del gabinete de Bush están o han estado ligados a las industrias estadounidenses armamentística y petrolífera del país) y una ideología ultra-conservadora apoyada por la derecha cristiana, han transformado esa tendencia inicial en todo un impulso a favor de una política exterior imperialista y unilateralista. Aunque hayan comenzado a surgir importantes voces críticas con la dirección que Bush está tomando ${ }^{52}$, el discurso maniqueo y excepcionalista del "Choque de Civilizaciones" sigue desgraciadamente presente en las declaraciones de altos cargos de la administración y en los medios de comunicación impidiendo, por una parte, el debate sobre la política exterior estadounidense tras el 11 de Septiembre y exacerbando, por otra, su inherente racismo y fanatismo intolerante contra lo árabe y/o islámico que, aunque presente con anterioridad, se ha visto alentado por la actitud de algunos políticos, comentaristas de televisión y líderes religiosos.

Como botón de muestra mencionaremos que, ante declaraciones tales como la realizada por el Fiscal General, John Ashcroft: "el islam es una religión en la cual Dios te pide que mandes a tu hijo ă la muerte por Él. El cristianismo es una fe en la cual Dios envió a su hijo a morir por ti”, ${ }^{\prime 3}$, el rechazo institucional no ha sido lo unánime y tajante que se hubiera

${ }^{51}$ Entre otros: Donald Rumsfeld, Secretario de Defensa, Paul Wolfowitz, Subsecretario de Defensa, y Dick Cheney, Vicepresidente.

${ }^{52}$ Algunos incluso miembros de la administración de Bush padre como son el ex Secretario de Estado, James Baker, y el ex Consejero de Seguridad Nacional, Brent Scowcroft.

53 "Islam is a religion in which God requires you to send your son to die for him. Christianity is a faith in which God sends his son to die for you." 
esperado si este alto cargo de la administración Bush hubiese dirigido palabras semejantes contra cualquier otra comunidad religiosa. Es significativo que sólo 17 miembros de la Cámara de Representantes estadounidense, compuesta por 435 congresistas, se unieron a la petición de que Ashcroft se retractase de sus declaraciones ${ }^{54}$.

Así mismo, los ataques del 11 de septiembre han favorecido a Israel impulsando el discurso pro-israelí en el seno de la sociedad estadounidense y su clase política. El fin de la Guerra Fría cuestionó el valor de este país como aliado estratégico en un mundo que se percibía ya libre de la amenaza del comunismo internacional, por lo que los israelíes optaron por justificar a partir de entonces sus acciones contra el pueblo palestino en el marco de su "lucha contra el terrorismo islámico". Como era de esperar, Israel ha aprovechado la conmoción internacional tras los ataques contra Estados Unidos para intentar legitimar su política con respecto a los palestinos, para lo que ha encontrado un apoyo fundamental entre algunos elementos de la derecha cristiana pro-israelí, particularmente sectores evangélicos, que disfrutan de cierta influencia en el ámbito político y mediático ${ }^{55}$.

Por si fuera poco, las medidas adoptadas por la administración Bush tras el 11 de Septiembre, que se han traducido en detenciones masivas de árabes y musulmanes, el endurecimiento de las restricciones que se aplican a inmigrantes y visitantes provenientes de países árabes, el cierre de instituciones benéficas musulmanas por la simple sospecha de que pudieran apoyar a organizaciones terroristas, la relajación de la normativa que regula la vigilancia de sospechosos, y un largo etcétera, además de provocar la protesta de organizaciones de derechos civiles por el carácter racialmente discriminatorio de dichas medidas, han provocado que los ciudadanos árabes y/o musulmanes no se sientan seguros en su propio país ${ }^{56}$.

Ante este auge de la animadversión hacia lo árabo-islámico, los árabes y musulmanes han reaccionado en su mayor parte retirándose de la escena pública por miedo, ${ }^{57}$ lo que ha perjudicado de manera significativa la labor de las organizaciones árabes y musulmanas que intentan fomentar la participación de estos colectivos en la vida política del país. En opinión de algunos activistas, la comunidad ha perdido así una oportunidad de oro para hacer frente de manera enérgica a estos elementos políticos y mediáticos que fomentan la mala imagen de lo arabo-islámico en Estados Unidos ${ }^{58}$.

\footnotetext{
${ }^{54}$ Eggen, Dan. "Alleged Remarks on Islam Prompt an Ashcroft Reply. Critics Urge a More Emphatic Repudiation of Comments" [Internet]. The Washington Post, 14 de febrero de 2002, pág. A31. Disponible en $<$ http://www.washingtonpost.com/ac2/wp-dyn/A7548-2002Feb13?language=printer>; "House Members ask Attorney General Ashcroft to repudiate anti-Islamic remarks", 8 de abril de 2002. Disponible en septiembre de 2002 en <http://www.house.gov/mckinney/news/pr020408.htm>.

${ }^{55}$ Wagner, Don. "For Zion’s Sake." Middle East Report 32, no. 223 (2002): 52-57.

${ }^{56}$ Sobre las medidas adoptadas por la administración Bush y su impacto en las comunidades árabe y musulmana estadounidenses, véase Cainkar, Louise. "No Longer Invisible: Arab and Muslim Exclusión after September 11". Middle East Report 32, no. 224 (2002): 22-29; Feldman, Keith. "American Justice, Ashcroft-Style". Middle East Repot 32, no. 224 (2002): 30-31; Hassan, Slah D. "Arabs, Race and the Post-September 11 National Secuity State". Middle East Report 32, no. 224 (2002): 16-21.

${ }^{57}$ Entrevista personal con Margaret Zaknoen.

${ }^{58}$ Entrevista personal con Khaled Elgindy; entrevista personal con Margaret Zaknoen.
} 
El acoso mediático y gubernamental ha llegado a tal extremo que, en el mes de octubre de 2002, las principales organizaciones musulmanas se han unido para emitir un comunicado al respecto. En él denuncian el aumento del discurso anti-islámico en el país y el hecho de que esta demonización que sufre la comunidad musulmana a manos de comentaristas de televisión de tendencias ultra-conservadoras y líderes evangélicos se vea alentada por el silencio del presidente Bush al respecto ${ }^{59}$. Sin embargo, la emisión de un comunicado no se antoja una iniciativa suficiente para hacer frente a la situación. A las comunidades árabe y musulmana estadounidenses les sigue costando hacer patente de manera enérgica y rotunda su protesta y rechazo a los ataques demagógicos y discriminatorios a los que se ven sometidas.

Esperemos que en un futuro no muy lejano este sector de la sociedad estadounidense aprenda de otras minorías, como la afroamericana, y emprenda de manera efectiva su propia lucha en contra de la discriminación étnica y religiosa y a favor de un mayor entendimiento intercultural.

${ }^{59}$ Middle East and North Africa Information List. "President asked to repudiate anti-islamic hate", mensaje $\mathrm{n}^{\circ} 237$, 10 de octubre de 2002, el texto completo del comunicado se puede consultar en: $<$ http://www.yourmailinglistprovider.com/pubarchive.phn?MENAinfo $>$. 

NOTAS Y RESEÑAS 
